\title{
Conceptualizaciones sobre la violencia de género en sentencias con jurados en la Provincia de Córdoba, Argentina
}

\author{
Conceptualizations of gender violence in jury trials in the \\ Province of Córdoba, Argentina
}

Conceitualizações sobre a violência de gênero nas sentenças de julgamentos pelo tribunal do júri na Província de Córdoba, Argentina

\section{María Eugenia Gastiazoro*}

\section{RESUMEN}

A partir de datos cuantitativos y cualitativos sobre sentencias Palabras clave: emitidas con jurados populares a lo largo del periodo 2005-2018, en la Provincia de Córdoba (Argentina), se analizó el impacto de la reforma penal que incorporó la agravante de femicidio en el femicidio, estereotipos, género, sentencias. discurso de las sentencias penales desde una mirada socio-jurídica feminista. Por una parte, se observó la mayor judicialización en la persecución penal de hechos sobre homicidios de mujeres por medio de su elevación a juicio oral con jurados y por otra, la construcción creciente de un discurso que aborda las condiciones sociales de opresión hacia las mujeres y cuestiona las interpretaciones restrictivas de la agravante de femicidio. Estos aspectos tensionan las perspectivas pasionales e individuales sostenidas en estereotipos de género que inciden en el sostenimiento y reproducción de este tipo de desigualdades.

\section{ABSTRACT}

Based on quantitative and qualitative data on sentences issued Keywords: by popular juries between 2005-2018 in the Province of Córdoba femicide, stereotypes, gender, sentences.

Doctora en Derecho y Ciencias Sociales por la Facultad de Derecho de la Universidad Nacional de Córdoba (UNC, Argentina). Investigadora Asistente (CIJS-CONICET). Docente de la Facultad de Derecho (UNC), Cátedra de Sociología Jurídica. E.-mail: megastiazoro@yahoo.com.ar 
(Argentina), the impact of the criminal reform (femicide) was analyzed from a feminist socio-legal perspective. On the one hand, greater judicialization was observed in the criminal prosecution of homicide against women, and on the other, the growing construction of a discourse that addresses the social conditions of oppression towards women and questions the restrictive interpretations of femicide. These aspects put a strain on perspectives based on gender stereotypes that have an impact on the continuity and reproduction of this type of inequality.

\section{RESUMO}

A partir de dados quantitativos e qualitativos sobre sentenças Palavras-chave: emitidas por júris populares no período de 2005-2018, na Província de Córdoba (Argentina), foi analisado o impacto da reforma penal que incorporou o agravante de feminicídio no discurso das feminicídio, estereótipos, gênero, sentenças. sentenças penais desde uma perspectiva sociojurídica feminista. Por um lado, observou-se a maior judicialização na persecução penal de atos de homicídio de mulheres através de sua elevação a julgamentos orais com júris e, por outro, a crescente construção de um discurso que aborda as condições sociais de opressão das mulheres e questiona as interpretações restritivas da circunstância agravante de feminicídio. Estes aspectos tensionam as perspectivas passionais e individuais sustentadas em estereótipos de gênero que incidem na manutenção e reprodução deste tipo de desigualdade. 


\section{Introducción}

En la última década, en distintos países de América Latina, se llevaron a cabo reformas legales de importancia en materia de derechos de las mujeres y disidencias LGTBQ $+^{2}$. Los progresos legales muestran los intercambios y diálogos entre los activismos sociales y el Estado (Cano \& Fernández Cordero, 2019). En Argentina, en el año 2012, la modificación del artículo 80 del Código Penal (Ley No 2679, 2012) significó la ampliación de delitos de homicidio agravados y se incorporaron aquellos perpetrados por un hombre sobre una mujer mediando violencia de género (art. 80 inc. 11 del Código Penal Argentino), y a quien lo hiciera "con el propósito de causar sufrimiento a una persona con la que se mantiene o ha mantenido una relación en los términos del inciso 1" (art. 80 inc. 12 del Código Penal Argentino). Si bien ambos incisos tienen correspondencia con las figuras de femicidio y femicidio vinculado, la ley no las nomina en esos términos ${ }^{3}$. Además, se agregaron otras causales de crímenes de odio: los producidos debido a la identidad de género y de la orientación sexual (art. 80 inc. 4 del Código Penal Argentino). Otro aspecto importante de la reforma fue la modificación de la agravante de vínculo: se amplió su aplicación “a la persona con quien mantiene o ha mantenido una relación de pareja, mediare o no convivencia" (art. 80 inc. 1 del Código Penal Argentino).

La reforma penal tuvo especial incidencia en la provincia de Córdoba, ya que, desde el año 2005, la Ley No 9.182 dispuso la integración (obligatoria) con jurados populares en las Cámaras con competencia en lo criminal a los efectos de resolver hechos elevados a juicio en

2 Particularmente en Argentina, se dictó la Ley de Educación Sexual Integral, (Ley No 26150, 2006), Ley de Protección Integral a las Mujeres (Ley № 26485, 2009), Ley de Matrimonio Igualitario (Ley No 26618, 2010), Ley de Identidad de Género (Ley No 26743, 2012), la reciente Ley Micaela de Capacitación Obligatoria en Género para personas que integran los tres poderes del Estado (Ley No27499, 2019) y el "Protocolo para la atención integral de las personas con derecho a la interrupción legal del embarazo (Resolución 1/2019, Ministerio de la Salud Argentina). A su vez, el debate abierto en 2018 sobre aborto legal y gratuito en el Congreso de la Nación, con la media sanción en la Cámara de Diputados, significó una fuerte discusión en la sociedad sobre los derechos de las mujeres y disidencias.

La normativa no utiliza la nominación de femicidio/feminicidio como en otros países de la región en los que se incorporó como un delito autónomo: Chile, Costa Rica, Guatemala y Nicaragua lo denominan femicidio y en El Salvador, México y Perú, feminicidio (Garita Vílchez, 2012). 
casos de homicidios agravados ${ }^{4}$. Esto significó el aumento de causas resueltas con jueces técnicos y legos elevadas a juicio oral sobre hechos tipificados en los nuevos términos -especialmente en casos de homicidios y tentativas de homicidios calificados por el vínculo y por violencia de género.

El mayor volumen de casos se intensificó en el marco de la mayor legitimidad y reconocimiento de la problemática de violencia de género, sobre todo a partir de la marcha Ni Una Menos 2015 (NUM) lo que forma parte de las demandas externas hacia un campo jurídico que como universo social, resulta relativamente independiente (Bourdieu, 2000). Como indica Martínez (2017) los reclamos de acciones concretas al Estado - entre ellos a los poderes judiciales- en materia de violencia hacia las mujeres cuentan con el respaldo mediático y estatal a diferencia de otros períodos en los que las demandas feministas eran desoídas ${ }^{5}$.

Bourdieu (2000) considera al derecho como:

La forma por excelencia del poder simbólico de nominación que crea las cosas nombradas y, en particular los grupos; el derecho confiere a esas realidades surgidas de sus operaciones de clasificación toda la permanencia, la de las cosas, que una institución histórica es capaz de conferir a instituciones históricas. (p. 202).

Como el mismo autor sugiere, "el derecho hace el mundo social, pero con la condición de no olvidar que él es hecho por ese mundo" (Bourdieu, 2000, p. 205) y es por esto mismo que los avances jurídicos en torno al reconocimiento legal de la categoría de femicidio no se pueden comprender sin las movilizaciones sociales y las discusiones que, desde el feminismo, han significado la visibilización pública de este conflicto, como en el corrimiento de la frontera de un derecho

\footnotetext{
$4 \quad$ La competencia abarca también otros delitos: los del fuero penal económico y anticorrupción administrativa, delitos contra la integridad sexual de la que resultare la muerte de la persona ofendida, secuestro extorsivo seguido de muerte, homicidio con motivo u ocasión de tortura y homicidio con motivo u ocasión de robo del Código Penal de la Nación (Ley No 9182, 2004, art. 2).

$5 \quad$ Aun cuando la violencia hacia las mujeres fuese públicamente combatida por los feminismos argentinos, anualmente, cada 25 de noviembre desde 1981, la demanda se hizo masiva hace apenas un par de años, tras la emergencia de un desgarrador grito: “ $\mathrm{Ni}$ una menos!", difundido a través de las redes sociales (Martínez, 2017, p. 2).
} 
que se presenta como neutral frente al género y que oculta su carácter patriarcal y androcéntrico. Justamente, antes de que el femicidio fuera reconocido legalmente en el código penal, y frente a las mismas resistencias de los juristas y jueces a utilizarlo una vez regulado, el término ya existía de hecho y se encontraba instalado en el uso cotidiano de la población como en los medios de comunicación (Segato, 2017). Sin embargo, la instalación de la figura de femicidio, como las que también implican a otros grupos en razón de su identidad de género y orientación sexual, abarca una dimensión ética que se evidencia siempre y cuando la normativa tenga esa "capacidad de impactar y modelar, con las categorías que consagra legislativa y jurídicamente, la sensibilidad ética de las personas" (Segato, 2017, p.127).

En este marco, la ley es un "poder simbólico de nominación" y, como tal, "crea las cosas nombradas y, en particular los grupos" (Bourdieu, 2000, p. 202), sin embargo, tal consagración implica cierta estabilidad que conlleva el riesgo de la reducción de las categorías jurídicas si la interpretación legal, como de los hechos, pierde la mirada histórica en el proceso de institucionalización. Es decir, si lo visibilizado en términos de femicidio queda circunscripto, como sugiere Trebisacce (2016), a una "matriz de inteligibilidad de las experiencias, resultado de una interpretación del funcionamiento de opresión de las mujeres, que anticipa las experiencias posibles de ser reconocidas como tales y las recorta de otras que no consiguen siquiera ser visualizadas". (p. 291).

Cano (2016) se pregunta sobre los límites y las potencias del discurso construido sobre la figura penal del femicidio al abordar el carácter productivo de la razón femicida. Este carácter productivo nos conecta con las teorías sobre el sistema jurídico como "tecnología de género" (Smart, 2000) el que funciona no solo como una sanción negativa que oprime a las mujeres sino también como productor de diferencias de género y de identidad. Es decir, como explica Kohen (2000), en referencia a la tercera fase del feminismo jurídico, el derecho y sus interpretaciones se revela como "un proceso de producción de identidades de género fijas más que como una simple aplicación de la ley a sujetos que ya tienen género previamente"(p. 98). La limitación de los sujetos dentro de un esquema de la diferencia sexual depone los aspectos múltiples y contradictorios (de Lauretis, 1996). Esto implica la simplificación de la violencia machista en dos categorías excluyentes en tér- 
minos de víctimas y culpables por medio de ontologías individualistas y personalizantes (Cano, 2016), que requieren “intervenciones asistencialistas y punitivas en términos heterosexistas, para mujeres-víctimas y varones-culpables" (Martínez, 2017, p.5). Sin embargo, también aparecen discursos que están "fuera de plano" (de Lauretis, 1996, p. 33) y que permiten una deconstrucción del género.

A partir de datos cuantitativos y cualitativos sobre sentencias emitidas con jurados populares a lo largo del periodo 2005-2018 en la Provincia de Córdoba, Argentina, se analizó el impacto de la reforma que incorporó la agravante de femicidio en el juzgamiento de delitos desde una mirada socio-jurídica feminista. Por una parte, se observó la mayor judicialización en la persecución penal de hechos sobre homicidios de mujeres por medio de su elevación a juicio oral con jurados y por otra, la construcción creciente de un discurso que aborda las condiciones sociales de opresión hacia las mujeres y cuestiona interpretaciones restrictivas de la agravante de femicidio. Estos aspectos tensionan las perspectivas pasionales e individuales sostenidas en estereotipos de género que inciden en el sostenimiento y reproducción de este tipo de desigualdades.

\section{Homicidios y tentativas sobre mujeres resueltos con jurados (2005-2017)}

La provincia de Córdoba fue pionera en la instauración del juicio por jurados, iniciándose con la figura del escabinado en 1998, extendido a los tribunales mixtos con mayoría lega en $2005^{6}$. Actualmente, tras

$6 \quad$ La Ley No 9182 establece un jurado de ocho personas compuesto por cuatro varones y cuatro mujeres, los cuales son elegidos aleatoriamente de un listado que se elabora anualmente por sorteo a partir del padrón electoral de la provincia. Siguiendo la letra de la ley, quienes integran el jurado tienen la responsabilidad de decidir sobre la existencia de los hechos llevados a proceso, como también de la participación de los imputados en el caso. La decisión se toma en conjunto con dos de los tres jueces técnicos que componen las cámaras en lo criminal de la provincia, por simple mayoría. Quien preside el tribunal solo vota en caso de empate, y es responsable de fundamentar el voto de los legos si deciden en un sentido diferente al de los camaristas. El procedimiento de esta ley se dirige hacia la oralización del proceso. Es por ello que los ciudadanos comunes reciben la información sobre el caso durante el debate, prohibiéndoseles tener acceso al expediente. Un trabajo exhaustivo de investigación sobre cultura jurídica vinculada a la implementación y consolidación del juicio por jurados en Córdoba se ha llevado a cabo por Bergoglio (2017). 
catorce años de su aplicación, la institución se encuentra consolidada dentro del proceso penal cordobés (Bergoglio, 2019) ${ }^{7}$.

En este apartado, se sistematizaron datos cuantitativos de 445 sentencias, de las cuales 160 corresponden a casos en los que mujeres fueron víctimas de delitos en hechos elevados a juicio por homicidio o tentativa de homicidio calificados u homicidios criminiscausae, en ocasión de robo o ataque sexual ${ }^{8}$ (Tabla 1 ).

El grueso de casos calificados por violencia de género luego de la reforma de 2012 fueron aquellos en los cuales se identificó algún tipo de vínculo previo o actual (pareja o expareja, matrimonio, noviazgo, etc.). Es decir, la mayoría de los casos comprendidos en términos de femicidio son los homicidios - o tentativas - hacia mujeres en ámbitos de lo doméstico-familiar o entre personas con vínculos afectivos cercanos. Si bien hay algunos hechos ocurridos en el espacio público —entre desconocidos - donde la calificación de género aparece, tales casos son excepcionales.

Como ya se marcó anteriormente, esta creciente penalización de causas de homicidios y tentativa reside en la ampliación de la noción de vínculo (reforma del Código Penal y Código Civil) y en el creciente compromiso con la problemática de género en el ámbito del poder judicial en un contexto social y político de mayor reconocimiento y visibilización de este tipo de opresiones. Sin embargo, al concentrarse la mayoría de los casos en la modalidad de "femicidios

\footnotetext{
Desde el año 2008, nuestro equipo de investigación, dirigido por la Dra. María Inés Bergoglio, lleva a cabo un trabajo exhaustivo sobre los jurados populares en la Provincia de Córdoba por medio de distintos proyectos subsidiados por SECYT (Resoluciones SECYT-UNC; 313/16, 162/12, 214/10 y 069/08).

8 Se sistematizaron las sentencias elevadas y resueltas en juicio oral sobre homicidios (consumados y tentativas) hacia mujeres a lo largo del período 2005-2017, emitidas por jurados populares en la Provincia de Córdoba. Se elaboró una clasificación de cinco categorías a los efectos de observar en el marco de qué relaciones y situaciones se produjeron los hechos. La primera, refiere a homicidios de mujeres en las cuales la relación entre víctima y victimario es sin vínculo, ya sea por tratarse de extraños o conocidos, pero sin la tipificación de vínculo (por ejemplo, mujeres atacadas por robo o sexualmente en la calle, su trabajo o en su casa, que luego terminó en homicidio). La segunda, comprende homicidios cometidos en relaciones donde existía vínculo actual o no de pareja, matrimonio o noviazgo, etc. La tercera y la cuarta, comprende los casos no consumados, es decir de tentativas de homicidios respecto de los mismos hechos de la primera y segundo clasificación. Por último, en la quinta categoría, fueron incluidos los delitos sobre mujeres ocurridos en relaciones familiares, por ejemplo, filicidios, donde la víctima fue mujer.
} 
íntimos", se podría considerar, al igual y como lo sugiere el informe de la Unidad Fiscal Especializada en Violencia contra las Mujeres de la Nación (UFEM) en su análisis sobre las primeras 50 sentencias de femicidios en el país, "una sub-representación vinculada al tipo de hechos que se consideran emergentes de la violencia de género" (Unidad Fiscal Especializada en Violencia contra las Mujeres de la Nación, 2017, p. 36).

Tabla 1

Sentencias sobre homicidios y tentativas de homicidios hacia mujeres, Córdoba (período 2005-2017)

\begin{tabular}{|c|c|c|c|c|}
\hline \multirow[b]{2}{*}{$\begin{array}{l}\text { Homicidios y tentativas de } \\
\text { homicidios hacia mujeres }\end{array}$} & \multicolumn{3}{|c|}{ Periodo } & \multirow[b]{2}{*}{ Total } \\
\hline & $\begin{array}{l}2005- \\
2009\end{array}$ & $\begin{array}{l}2010- \\
2013\end{array}$ & $\begin{array}{l}2014- \\
2017\end{array}$ & \\
\hline \multirow{2}{*}{$\begin{array}{l}\text { Homicidio, sin vínculo/ } \\
\text { conocido o no, atacadas por } \\
\text { robo y/o sexualmente en la } \\
\text { calle, su trabajo o en su casa. }\end{array}$} & 14 & 17 & 16 & 47 \\
\hline & $41.2 \%$ & $42.5 \%$ & $18.6 \%$ & $29.4 \%$ \\
\hline \multirow{2}{*}{$\begin{array}{l}\text { Homicidio en relaciones de } \\
\text { pareja, noviazgo, matrimonio, } \\
\text { ex. }\end{array}$} & 6 & 11 & 32 & 49 \\
\hline & $17.6 \%$ & $27.5 \%$ & $37.2 \%$ & $30.6 \%$ \\
\hline \multirow{2}{*}{$\begin{array}{l}\text { Tentativa homicidio, } \\
\text { sin vínculo/ conocido o } \\
\text { no, atacadas por robo o } \\
\text { sexualmente en la calle, su } \\
\text { trabajo o en su casa. }\end{array}$} & 1 & 3 & 3 & 7 \\
\hline & $2.9 \%$ & $7.5 \%$ & $3.5 \%$ & $4.4 \%$ \\
\hline \multirow{2}{*}{$\begin{array}{l}\text { Tentativa homicidio en } \\
\text { relaciones de pareja, noviazgo, } \\
\text { matrimonio, ex. }\end{array}$} & 4 & 5 & 26 & 35 \\
\hline & $11.8 \%$ & $12.5 \%$ & $30.2 \%$ & $21.9 \%$ \\
\hline \multirow{2}{*}{$\begin{array}{l}\text { Homicidio y tentativas en el } \\
\text { marco de relaciones de familia } \\
\text { (hija/madre/pariente). }\end{array}$} & 9 & 4 & 9 & 22 \\
\hline & $26.5 \%$ & $10.0 \%$ & $10.5 \%$ & $13.8 \%$ \\
\hline \multirow{2}{*}{ Total } & 34 & 40 & 86 & 160 \\
\hline & $100.0 \%$ & $100.0 \%$ & $100.0 \%$ & $100.0 \%$ \\
\hline
\end{tabular}

Fuente: Datos procesados en esta investigación sobre 160 sentencias (2005-2017).

La tabla 1 muestra la distribución de sentencias en tres periodos de tiempo a lo largo de 2005-2017. El primero, marca el inicio de la implementación de la institución, el segundo y el tercero, la consolidación del sistema de jurados. Se observa un claro aumento en el total de casos procesados con jurados en el periodo 2014-2017, los que repre- 
sentan más del doble (86) respecto de los periodos anteriores (34 en 2005-2009 y 40 en 2010-2013).

A su vez, el mayor porcentaje de casos se concentra en el último periodo, en homicidios y tentativas de homicidios con vínculo, lo que contrasta con los anteriores en los que la mayor cantidad estaba representada por aquellos donde no había vínculo. Aunque el aumento de este tipo de sentencias comienza en el segundo periodo (finales de 2012, con la reforma implementada), la cifra llega a triplicarse en el tercero. También, el salto abrupto se observa respecto de los casos de tentativas de homicidios en relaciones de pareja, noviazgo o matrimonio: entre 2014 y 2017, el número de casos decididos con jurados populares representan cinco veces más que con respecto a 2010-2013.

Por otra parte, la siguiente tabla permite analizar la cantidad de absoluciones y condenas. Sobre el crecimiento de causas elevadas a juicio, en términos de tentativas de homicidio calificadas por el vínculo, se observó un aumento de la penalización. Los casos en los cuales el imputado fue absuelto representaron solo el $4.0 \%$ del total en el periodo 2014-2017, mientras que, en el período anterior, ese porcentaje fue del $33.0 \%$. Sin embargo, cabe destacar que este aumento se encuentra ligado principalmente a un aumento en la judicialización de la persecución penal de este tipo de hechos. Es decir, hay una mayor cantidad de hechos que, en la actualidad, son alcanzados e identificados en términos jurídicos dentro del tipo penal de homicidio calificado, consumados o no, por el vínculo y por el género, y elevados a juicio. En este sentido, son más las causas tramitadas judicialmente donde el imputado es pasible de recibir una pena máxima (como la condena perpetua en casos de homicidios) o hasta más de 16 años de prisión en casos de tentativas (en concurso con otros delitos). Por otra parte, el compromiso del poder judicial, asumido en estos casos, se observa, por ejemplo, en continuar con la causa a pesar de que la víctima mujer se retracte del hecho. 
Tabla 2

Absoluciones y condenas en casos de homicidios y tentativas sobre mujeres con vínculo, Córdoba (2005-2017)

\begin{tabular}{|c|c|c|c|c|}
\hline & \multirow{2}{*}{$\begin{array}{l}\text { Periodo } \\
\text { Absolución }\end{array}$} & \multicolumn{2}{|c|}{ Tipo } & \\
\hline & & Condena & Total & \\
\hline \multirow[t]{2}{*}{ 2005-2009 } & \multirow{2}{*}{$\begin{array}{l}\text { Homicidio } \\
\text { Tentativa de homicidio }\end{array}$} & & $100.0 \%$ & $100.0 \%$ \\
\hline & & $20.0 \%$ & $80.0 \%$ & $100.0 \%$ \\
\hline \multirow[t]{2}{*}{ 2010-2013 } & \multirow{2}{*}{$\begin{array}{l}\text { Homicidio } \\
\text { Tentativa de homicidio }\end{array}$} & $14.3 \%$ & $85.7 \%$ & $100.0 \%$ \\
\hline & & $33.3 \%$ & $66.7 \%$ & $100.0 \%$ \\
\hline \multirow[t]{2}{*}{ 2014-2017 } & \multirow{2}{*}{$\begin{array}{l}\text { Homicidio } \\
\text { Tentativa de homicidio }\end{array}$} & & $100.0 \%$ & $100.0 \%$ \\
\hline & & $4.0 \%$ & $96.0 \%$ & $100.0 \%$ \\
\hline
\end{tabular}

Fuente: Datos procesados en esta investigación sobre 84 sentencias (2005-2017).

Los datos muestran el creciente número de causas que llegaron a juicio oral con jurados en las cuales hay vínculos entre víctimas y victimarios. A lo largo del tiempo, las prácticas judiciales se han ido robusteciendo en torno a la problemática, así, por ejemplo, la discusión sobre los calificantes de vínculo y violencia de género recién quedó zanjada en el fallo del Tribunal Superior de Justicia (TSJ) de la Sala Penal, sentencia que resuelve la apelación en el caso Lizarralde (S. 56, 2017). No obstante, todavía se encuentran decisiones judiciales discutibles y contradictorias en términos de lo que marcó el máximo tribunal en su momento. La sentencia emitida por el Tribunal Superior de Justicia de la provincia de Córdoba el 9 de marzo de 2017, luego de la concurrida marcha que conmemora el Día Internacional de la Mujer, 8M, resolvió la apelación del fallo sobre el crimen de Paola Acosta.Sobre esta decisión remarcamos tres aspectos claves:

Primero, y de acuerdo a lo expresado por el máximo tribunal, la nominalización de la violencia de género requiere correr la frontera de las clásicas categorías de dogmática jurídica, es decir entiende que:

La mayoría de los episodios de violencia (...) son el resultado de una serie de condicionamientos que no se conforman con los estándares jurídicos clásicos sino que (...) exigen una tarea más profunda por parte de los órganos judiciales que excede las clásicas categorías de dogmática jurídica. (TSJ, Lizarralde, S. 56, 2017, p. 125). 
Segundo, la interpretación del TSJ, desprivatiza el sentido común (sostenido en los medios, como en la justicia) que indica que la calificación de femicidio solo es posible si el hecho ocurrió en el ámbito de lo familiar y/o relaciones de pareja. Si bien declara que es el caso común, difundido en tiempos recientes como femicidio, al contrario, el TSJ reafirma la definición del art. 2 de la Convención Belém do Pará, en la cual la proyección de la violencia de género es entendida de modo transversal.

Tercero, remarca la desigualdad de género como una dimensión social para entender el contexto de violencia de género en el cual se desarrollaron los hechos. Sin embargo, subraya que esto requiere un esfuerzo mayor para los decisores, ya que importa

una aguda sensibilidad para detectar los indicadores de desigualdad que colocan a la mujer en una situación de inferioridad en la que el hombre ejerciendo su poder la lesiona física, sexual o psicológicamente, o de un modo más extremo, le causa su muerte (TSJ, Lizarralde, S. 56, 2017, p. 128).

\section{Corpus de análisis: sentencias que contienen en su texto la palabra "femicidio"}

Se seleccionaron fallos con los efectos de analizar las conceptualizaciones sobre la violencia de género en decisiones tomadas entre jueces legos y jurados populares en la provincia de Córdoba9 ${ }^{9}$. La unidad de análisis se integró con 33 sentencias, en las cuales se identificó la palabra femicidio, ya sea que se la enunció y/o discutió a lo largo de su discurso. Dicho criterio de selección se justificó en que, si bien la ley penal no nomina este tipo de delito como femicidio, resulta curioso que la palabra se haya instalado en los medios de comunicación, en la población en general y en los mismos operadores de justicia -incluso antes de la reforma. En Córdoba, recién pasados los tres años de la reforma penal el término comenzó a generalizarse en su uso en el cuerpo de las sentencias. La palabra resulta un emergente del discurso jurídico que nos marca una evidencia en torno a reflexionar sobre sus

\footnotetext{
$9 \quad$ En el anexo se encuentra la tabla con el detalle de las sentencias que conforman el corpus seleccionado.
} 
significados en un contexto de mayor politización y reconocimiento de las demandas feministas.

Sin embargo, creemos de importancia remarcar los límites que el recorte del corpus implica. El análisis cualitativo, en esta parte del trabajo, resulta de la aplicación particular a la unidad de análisis construida en esta fase de la investigación. En este sentido, los alcances de los datos presentados no son extensivos a todo el universo de casos sobre violencia de género resueltos con jurados populares (desde el año 2005 hasta mediados del 2018). Los resultados son aplicables al particular caso del conjunto de decisiones judiciales seleccionadas en esta parte (de un universo reunido de una investigación que se encuentra en curso) y sus conclusiones permiten hipotetizar sobre los caminos a seguir dentro de esta línea. En este sentido, es un "análisis de instancias específicas (...) en las prácticas del derecho" (Kohen, 2000, p. 99), sobre el cual trabajos de campo posteriores permitirán completar las otras caras del objeto de estudio. Se abordaron las definiciones de femicidio que integran los fallos en los que se puso en discusión esta problemática y las representaciones sociales de la violencia de género creadas y recreadas hacia el interior del poder judicial como hacia la sociedad en general.

Se utilizaron técnicas documentales y análisis de contenido en la recolección de los datos cualitativos de las sentencias seleccionadas (producciones escritas). El estudio se concentró en dos aspectos claves que permitieron abordar las conceptualizaciones de la violencia de género: los estereotipos de género y el contexto de la violencia.

El corpus quedó conformado con los siguientes fallos, que se enumeran de acuerdo al año de emisión: en 2011, un caso pionero - caso Ortega-, en el cual la palabra apareció a instancias del fiscal de la cámara, quien asentó los hechos en la categoría de femicidio - tentativa de homicidio; en 2015 la palabra se encontró en el cuerpo de ocho sentencias (si bien ya había fallos que aplicaban la agravante de violencia de género de la reforma del Código Penal con anterioridad al año 2015, no usaban el término para nombrar el delito); en 2016 se identificaron doce sentencias; en 2017 seis; y en 2018 (hasta la mitad de año), otras seis.

La mayoría de los casos del corpus de análisis tuvieron como víctimas mujeres cisgénero (en Córdoba, el primer y único caso juzga- 
do como femicidio sobre una mujer travesti fue recién en agosto de $2019^{10}$ ). En dos casos, en los que se discutió sobre el femicidio vinculado, las víctimas fueron hombres. Solo una sentencia fue de un hombre asesinado por su pareja mujer, la que se integró en el corpus, ya que se problematizó la definición de femicidio para abordar la cuestión del vínculo. Se trató de hechos entre personas con un vínculo cercano afectivo, ya sea de pareja y/o de ámbito familiar, lo que indica la subrepresentación de casos de femicidios no íntimos y crímenes de odio por género y orientación sexual (Gastiazoro, 2018). Solo tres fueron sobre personas desconocidas, en los cuales mujeres fueron atacadas en la calle. Por último, todas las personas imputadas y sometidas al juicio oral ante jurados fueron condenadas.

\section{Estereotipos de género}

Una de las cuestiones que marca el Modelo de protocolo latinoamericano de investigación de las muertes violentas de mujeres por razones de género (femicidio/feminicidio), del año 2014, y que resulta problemático en la administración de justicia, son los estereotipos de género, los que afectan el derecho de las mujeres en el acceso a la justicia:

Los mitos e ideas sobre roles y estereotipos de género preconcebidos y usados por los distintos actores del proceso afectan el derecho de las mujeres de acceder a la justicia y de contar con un juicio imparcial, lo que reproduce las desigualdades de género. (Oficina Regional para América Central del Alto Comisionado de las Naciones Unidas para los Derechos Humanos \& Oficina Regional para las Américas y el Caribe de la Entidad de las Naciones Unidas para la Igualdad de Género y el Empoderamiento de las Mujeres, 2014, p. 24).

Turvey (1999) se refiere tanto a la deificación de la víctima, en referencia a su idealización, como a su envilecimiento, por medio del cual se destacan características que hacen que sea considerada como propiciadora o merecedora de lo ocurrido. También, el agresor puede

\footnotetext{
$10 \quad$ El antecedente importante en el país fue la sentencia sobre el crimen de Diana Sacayán, en la ciudad de Buenos Aires. En julio de 2018, el Tribunal Oral en lo Criminal y Correccional $\mathrm{N}^{\circ} 4(\mathrm{CABA})$ dictó el primer fallo condenatorio por travesticidio (crímenes de odio - entre ellos, el odio a la identidad de género) y femicidio (violencia de género).
} 
ser deificado y la víctima envilecida, presentando argumentos en la justificación del primero. Investigaciones exploratorias previas sobre las primeras sentencias del periodo 2005-2009 emitidas en Córdoba con jurados populares ${ }^{11}$, mostraron construcciones patriarcales en decisiones donde las mujeres fueron víctimas de homicidio o su tentativa, ya sea para aplicar una pena alta al responsable del delito o para justificar el actuar del imputado y disminuir la calificación legal, e incluso eximirlo de pena. Así, por ejemplo, se observó la justificación de la conducta de agresión en actos de la víctima como provocadores del hecho (mujer que se negó a tener relaciones sexuales con su marido o esposa que se salió del rol tradicional de sujeción familiar) y el alcoholismo del imputado como causal eximente de la violencia cometida y su consecuente absolución (Sánchez, Gastiazoro, Rojo \& Gilli, 2010). Los estereotipos sobre las mujeres significan que el acceso a la justicia se distribuye en torno a construcciones sociales de "la buena" o "la mala" víctima (sumisa/decidida; vulnerable/ empoderada; débil/fuerte; pasiva/activa). Esto, a su vez, se conecta con la identificación del contexto de violencia de género. En un principio, las decisiones condicionaron la valoración del emergente de violencia en base a la dicotomía adentro/afuera, familiar/no familiar o vínculo/no vínculo y restringían la agravante de violencia de género al espacio de lo íntimo (situado en relaciones donde hay vínculo de pareja o conyugalidad) frente a hechos ocurridos entre personas extrañas o sin vínculo (lo que ubica a ese contexto en el espacio del afuera y de lo público).

Ambos aspectos de análisis - estereotipos y contexto- indican el funcionamiento de categorías dicotómicas en la interpretación de los hechos que actúan en términos de tecnología de género. De Lauretis (1996), en el marco de la teoría de Foucault, plantea la paradoja siguiente: las prohibiciones y regulaciones relativas a los comportamientos sexuales, ya sean hablados por autoridades religiosas, legales o científicas, lejos de constreñir o reprimir la sexualidad, por el contrario, la han producido y continúan haciéndolo en el sentido que la maquinaria industrial produce bienes o comodidades $\mathrm{y}$, al hacerlo,

$11 \quad$ Investigación realizada en el marco del proyecto de investigación subsidiado por SECYT (Res. SECYT-UNC 069/08, dirigido por la Dra. María Inés Bergoglio). 
también produce relaciones sociales. De ahí la noción de tecnología del sexo, que define como un conjunto de técnicas para maximizar la vida que han sido desarrolladas y desplegadas por la burguesía desde finales del siglo XVIII para asegurar su supervivencia de clase y su hegemonía permanente (de Lauretis, 1996). Estos discursos, implementados a través de la pedagogía, la medicina, la demografía y la economía, fueron fijados o sostenidos por las instituciones del Estado y se tornaron especialmente focalizados en la familia; sirvieron para difundir e implantar esas figuras y modos de conocimiento en cada individuo, familia e institución. Esta tecnología, remarcó, hizo del sexo no solo un asunto secular, sino también un asunto del Estado: "para ser más exactos, el sexo se convirtió en una materia que requería del cuerpo social en su totalidad y virtualmente de todos sus individuos, que se pusieran a sí mismos bajo vigilancia" (de Lauretis, 1996, p. 8).

De acuerdo con Smart (2000), la aplicación de la perspectiva de de Lauretis en el orden jurídico evidencia que

existen estrategias que dan lugar al advenimiento de la Mujer y las mujeres. Estas estrategias, (entre las cuales incluyo el derecho así como la disciplina), varían en función de la historia y la cultura; son, además contradictorias y hasta ambivalentes. Igualmente podría tratarse de estrategias que no provienen de autor alguno. (pp. 42-43).

La complejidad del derecho se revela también en que es un instrumento para el cambio social. Esto implica la importancia de las investigaciones de "rastrear la manera en que las mujeres se han resistido a las construcciones de género o las han negociado" (Smart, 2000, p. 49), como también de deconstruir la mujer del discurso jurídico a los efectos de no recrear determinismos que implican su encasillamiento dentro de un modelo homogéneo.

Las posiciones y subjetivaciones que el discurso jurídico construye se revelan en los fallos del corpus seleccionado, donde la mujer es definida como víctima mujer vulnerable. Sin embargo, el fallo del TSJ fijó posición al prescribir: "las víctimas no deben tener algún rasgo especial en su carácter para adquirir dicho estado" (TSJ, Lizarralde, S. 56, 2017, p. 125).

Ciertas representaciones discursivas suelen utilizarse para enmarcar - o no- la violencia de género de los hechos. En los siguien- 
tes casos, características fuertes de la víctima fueron señaladas en su contra para justificar el accionar y agresión del imputado. Esto llevó a los decisores a considerar la relación entre víctima y victimario en paridad de condiciones y, en consecuencia, rechazar la desigualdad de género.

El primer caso pionero en el cual el fiscal (coadyuvante) de cámara planteó la acusación en términos de tentativa de homicidio calificado, y el hecho en el marco de violencia de género y femicidio, fue en el año 2011-antes de la reforma del Código Penal. Los jurados, en mayoría (seis), establecieron que no hubo violencia de género sobre un análisis de las características de la mujer víctima del hecho. Sostuvieron que no se trataba del "caso típico de una mujer golpeada por su marido, ya que no le tenía miedo e incluso tenía amante". Remarcaron, además: "Este se trató de un caso de violencia familiar entre el acusado y su mujer (...) Desde ningún punto de vista entendemos que se hayan evidenciado elementos de violencia de género ni de femicidio, como marcó el Fis-

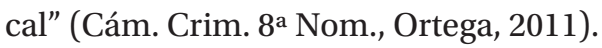

En 2015, en el caso Lizarralde, uno de los ejes de la decisión fueron las características de la víctima. Sostuvieron que para encuadrar el caso en violencia de género se requería estar ante una víctima mujer vulnerable, en el marco de relaciones de desigualdad y de poder asimétricas entre los sexos, que subordinen a la mujer. Apoyados en la pieza acusatoria sostuvieron la siguiente descripción:

No se trataba de una mujer que se colocaba a sí misma en el rol fijado socioculturalmente para el género femenino, que tolera y soporta toda conducta abusiva del hombre, sino que muy por el contrario, se mostró como una persona decidida a defender su derecho y los de su hija (...) Todo lo dicho nos aleja de esa mujer vulnerable, sumisa, dominada, víctima de una desigualdad de poder y nos coloca frente a una mujer fuerte, decidida, pero atacada sorpresiva y alevosamente. (Cám. Crim. 11 a Nom., Lizarralde, 2015).

La decisión de no calificación como femicidio se sostuvo sobre el extremo de no estar ante una víctima desposeída, abandonada, vulnerable. Esto evidencia la construcción de una imagen en términos de "mala víctima" en contraposición a la "buena víctima" como vulnerable y pasiva (Equipo Latinoamericano de Justicia y Género, 2015). 
Sin embargo, la asunción de un rol activo por parte de la víctima como justificativo de la negación en definitiva del acceso a la justicia fue puesta en cuestión en otros fallos y será la línea que marcará, después, el Tribunal Superior de Justicia de Córdoba, como ya se indicó en párrafos anteriores. En este orden, se registraron sentencias en las cuales los jueces, en unanimidad con jurados, sostuvieron que las actitudes fuertes, activas o que implicaron la puesta en cuestión por parte de la mujer de la relación de sometimiento no debió ser considerado como un punto que los pone en pie de igualdad. En el siguiente fallo, los jueces calificaron el caso como femicidio, a pesar de que el fiscal no lo consideró. Sostuvieron que el lugar activo que asume la mujer en el hecho, al poner en cuestión el vínculo subordinado, no se debe considerar como un elemento nivelador entre víctima y victimario: "En un contexto de violencia de género (asimétrico, subordinante, sometedor), la puesta en cuestión de la histórica víctima (a fin de acabar con aquel vínculo mortificante) comportó una afrenta insoportable para la hegemonía machista del autor" (Cám. Crim. 4ª Nom., Díaz, 2015).

Por el contrario, la caracterización de la "mala víctima" en los casos anteriores se opone al de "buena víctima", lo que también implica estereotipación a los efectos de ser reconocida en sus derechos ${ }^{12}$. En el siguiente fallo, se hace hincapié en sus sentimientos de miedo, temor y pasividad y en la relación de posesión/cosificación y humillación del varón respecto de la mujer. Estas identificaciones se utilizaron para justificar y encuadrar la relación y el hecho en términos de violencia de género, y sentenciar femicidio.

La relación de temor de (...) hacia (...) existía, y era de tal magnitud en razón de las amenazas de muerte, que la mujer nunca se animó a denunciarlas. Pero ella dijo que su marido le decía palabras que

\footnotetext{
12 En el marco de un discurso legal informado en teoría feminista, se asigna a las mujeres lugares de la debilidad y ausencia de poder, sustrayéndole la posibilidad de acción y violencia al señalarlas como víctimas pasivas, relegando las acciones empoderantes que implican la descalificación del sujeto en el pedido de justicia (Trebisacce, 2016). Sin embargo, lo que más remarca la autora es el discurso jurídico que se vuelve discurso performático de la realidad social y, en este sentido, "ya no es que traducimos nuestros problemas a sus términos, sino que sus términos definen nuestros problemas" (Trebisacce, 2016, p. 293). Como tal, concluye que la condición de víctima se concibe como un relato que determina toda la verdad de la situación —obstruyendo la complejidad de la realidad como otras potencialidades de los sujetos- y no como una estrategia frente a una sociedad patriarcal, racista y capitalista.
} 
demostraba que la consideraba su posesión: "si no sos mía no sos de nadie", y que su esposa era para Medina una cosa de quien podía disponer como él deseaba, sin tomar en cuenta que era una persona con derechos, con opiniones, que podía tomar decisiones (...) aunque a él no le gustaran. (Cám. Crim. 7ª Nom., Frías, 2015).

\section{Contexto de violencia de género}

Una de las cuestiones que marcaron los decisores, para los efectos de encuadrar un caso en términos de femicidio, fue la definición del contexto de violencia de género. En un principio, ese contexto fue reducido al ámbito íntimo, familiar, de relaciones cercanas sexo-afectivas sostenidas en el tiempo como tal, solo se comprendía la calificante en ese marco. En esta línea, los pocos casos en los que se abordó la agravante de femicidio vinculado emergieron de situaciones donde hubo vínculo de pareja.

Esta restricción se puso progresivamente en cuestión: la violencia de género puede tener lugar en relaciones interpersonales de la familia como también en cualquier otro ámbito de la sociedad y de parte de cualquier persona. Esta interpretación se ha construido en el marco de una legislación supranacional —la Convención de Belém do Pará. Es la posición de desigualdad y relación de dominación y violencia lo que determina el contexto de violencia de género. Esto implica la irrelevancia de la división público/privado en la determinación de la calificante. En este punto, resulta de importancia pensar en el problema de la privatización del concepto de femicidio/feminicidio. El estudio de Segato (2017) nos sugiere la pregunta sobre quiénes quedan narradas/ os en el discurso de femicidio ${ }^{13}$. La autora cuestiona fuertemente la privatización del concepto de feminicidio en el marco de la oposición jerárquica moderna de lo público y lo privado, donde lo primero es de interés general y lo segundo, parcial y particular, y propugna instalar las relaciones de género en una plataforma de importancia general.

13 En este sentido, una de las cuestiones que marca la autora es el cambio de escena tradicional de los crímenes de género para la región, donde observa que contrariamente a lo que el sentido común dispone:

los crímenes de género en la intimidad van decreciendo en número notablemente (...) la impersonalidad es un trazo que se afinca en los crímenes de género, y que esto se encuentra asociado a los escenarios de creciente conflictividad, es decir, de las nuevas formas de guerra, caracterizadas por la informalidad. (Segato, 2017, p.137). 
Esto implica que "introduciremos retóricamente en el sentido común patriarcal el carácter público de la experiencia femenina y validaremos su victimización como problema del interés general" (Segato, 2017, p.149). Es esta validación, como problema general y de carácter público, la que ha quedado plasmada y legitimada (en la sociedad como en los medios) a partir de NUM en 2015, para salir del marco de lo privado e individual y posicionarse en el centro de reclamos oídos por el Estado.

\section{Femicidio íntimo o vincular}

Las definiciones de femicidio restringidas al marco de relaciones de parejas sostenidas en el tiempo (no breve ni transitorio) se encontraron, principalmente, en sentencias del año 2015 y 2016 del corpus seleccionado. En el siguiente caso, los jueces no tipificaron el hecho como femicidio ya que en su interpretación la norma solo contempla el "íntimo". Fueron seis jurados en mayoría quienes decidieron que no hubo una relación de pareja, en consecuencia, los jueces al limitar el femicidio solo a ese contexto, no lo encuadraron bajo la calificante de violencia de género:

Ahora bien, sobre esta muy relevante cuestión, resulta que tras la correspondiente del Tribunal, seis de los Sres. Jurados populares, coincidieron en determinar que dicha relación de pareja en modo alguno se configuraba en el hecho (...) Por lo tanto, quedan comprendidos en la agravante el homicidio del concubino y de la novia, siempre que haya habido una "relación de pareja" entre el agresor y la víctima, situación que excluye las meras relaciones pasajeras, transitorias o amistosas. Como se puede apreciar, de las clases conocidas doctrinariamente, el tipo penal comprende sólo el denominado "femicidio íntimo", cuando se trate del asesinato de una mujer, con quien el agresor haya tenido una relación afectiva, familiar o de pareja. (Cám. Crim. 7ª Nom., Rodríguez, 2015).

La reducción del femicidio al ámbito de lo íntimo implicó la discusión entre la definición de violencia familiar por sobre la violencia de género. En los casos en que los decisores utilizaron esta distinción para los efectos de no aplicar la calificante de femicidio se observó que la diferenciación de los términos no resultó clara, ni tampoco se profundizó sobre la violencia doméstica como uno de los ámbitos donde se 
produce la de género, siendo un reducto de importancia en el sostenimiento del poder patriarcal (Jelin, 2010).

En la siguiente sentencia hubo disidencias al respecto. De acuerdo con la deliberación de la mayoría del tribunal, conformada por siete miembros - dos jueces y cinco jurados-, hubo violencia familiar pero no de género:

Ahora bien, la existencia de un contexto de violencia familiar no permite predicar, per se, que la criminalidad de (...) se vio impulsada por una pura cuestión de género. En otras palabras: que la víctima sea una mujer y que el hecho ocurra en un contexto de violencia familiar, no necesariamente debe conducir a la aplicación, en el sub judice, de la figura agravada de conato de femicidio. (Cám.

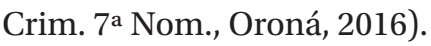

Refuerza esta interpretación la posición de un jurado en minoría que estuvo por la absolución del imputado. Sin embargo, en este mismo caso, dos jurados en minoría disintieron; sostuvieron que hubo violencia doméstica y de género, con fundamentos sobre la relación desigual de poder producida en el ámbito familiar:

$\mathrm{Al}$ respecto, debe considerarse que, en opinión de los jurados, estamos en presencia de violencia doméstica y de género, en un contexto donde el varón aparece ejerciendo todo su poder en relación a una víctima mujer, a la que intimida y quien no puede opinar en un plano de igual. (Cám. Crim. 7ª Nom., Oroná, 2016).

\section{Femicidio en la comunidad, no íntimo o público}

En 2016, el fallo de la ciudad de Río Cuarto amplió la noción de femicidio, aplicándolo en el caso de una agresión en la calle hacia una mujer. Los jueces hicieron hincapié en el contexto; el contexto de una violencia de género en la comunidad se desprende del mismo hecho y no del vínculo previo que tienen las personas, como lo sostienen las interpretaciones del femicidio que reducen su comprensión a relaciones con vínculo:

También puede gestarse este tipo de violencia en un ámbito distinto al doméstico, como puede ser en la comunidad. En este tipo de escenario, donde no hay ni hubo relación previa, la violencia de género se debe desprender del mismo hecho - ese debe ser el contex- 
to (...) La expresión violencia de género no refiere a ninguna relación previa entre víctima y victimario; no alude al momento en que debe ejecutarse la violencia; no menciona si esa violencia pudo ser previa y no manifestarse expresamente en el acto homicida. (Cám. Crim., Río Cuarto, Herrera, 2016).

Cabe destacar que en este mismo caso uno de los jueces - en disidencia con sus pares- rechazó aplicar la figura de femicidio no íntimo como también la de femicidio por conexión, concluyendo que la reforma penal solo abarca el íntimo o vincular.

Por otra parte, sobre la circunstancia de violencia de género que califica la tentativa de homicidio, no se le dio lugar a los jurados para que voten sobre ese aspecto de los hechos; solo decidieron respecto de la existencia del hecho, pero no sobre la violencia de género, cuestión criticable, ya que forma parte de los hechos y sobre lo cual los jurados también deberían emitir su opinión.

En el año 2018, un caso que tuvo resonancia en los medios -en el cual una mujer fue atacada en la calle, abusada y asesinada por un desconocido en un pueblo del interior de la provincia- fue sentenciado como femicidio. Los decisores siguieron la clasificación más amplia de femicidio en la cual incluyeron tres tipos de modalidad: íntimo, no íntimo - este fue el caso en cuestión-y vinculado:

Abuso sexual con acceso y homicidio calificado criminiscausae y femicidio en concurso real, en los términos de los arts. 45, 119, $3^{\circ}$ párrafo, 80 inc. $7^{\circ}$ y $11^{\circ}$, y 55 del C.P. Coincide parcialmente con la clasificación de femicidios contenida en el Modelo de protocolo latinoamericano de investigación de las muertes violentas de mujeres por razones de género femicidio/feminicidio de ONU Mujeres, el cual distingue el íntimo o vincular del no íntimo al que define como “...la muerte de una mujer cometida por un hombre desconocido con quien la víctima no tenía ningún tipo de relación. Por ejemplo, una agresión sexual que culmina en el asesinato de una mujer a manos de un extraño". (Cám. Crim. Villa María, Retamar, 2018).

De las sentencias analizadas, se concluye que, si bien se encuentra la conceptualización del femicidio en diferentes ámbitos, sin embargo, se evidencia cierta resistencia a utilizar la agravante si el hecho no se ajusta en el tipo íntimo, como se dispone en la siguiente sentencia: 
En la presente no existió por parte del imputado una violencia económica y patrimonial, ni simbólica contra la víctima, y si bien ha quedado acreditado que existieron violencia física, y sexual (y porque no tal vez psicológica), en el mismo momento consumativo ello no nos permite inferir con certeza que la misma responda a violencia de género. (Cám. Crim. Río Tercero, Rivero, 2017).

\section{Femicidio vinculado}

En el corpus seleccionado, dos fallos refieren a "femicidio vinculado", contemplado en el art.80, inc. 12 del Código Penal Argentino). En el primero, los decisores rechazaron el agravante, ya que justificaron el accionar del imputado, quien mató a la nueva pareja - un hombrede su ex esposa, en su intención de conservar la familia, y no de generar un daño hacia ella. Como se observa en otras investigaciones (Rodríguez \& Chejter, 2014), se minimizó la cuestión, protegiendo el ideario de la familia patriarcal más que a la mujer víctima de violencia:

También hay que recordar la anotación en el cuaderno secuestrado en el domicilio habitado..., donde a mano alzado se lee una anotación que dice: "que feo cuando hacés todo $\mathrm{x}$ una familia feliz y por atrás te clavan con un puñal sin piedad para destruirte", en clara referencia a las expectativas que tenía Heredia en recuperar la estructura familiar; insisto, aun cuando fuera en forma patológica. No hay elemento de prueba alguno que permita concluir que mataba para infligir dolor a (...), sino por el contrario, esos elementos permiten concluir que su propósito era volver a tener la familia y para ello eliminó a (...). (Cám. Crim. Río Tercero, Heredia, 2017).

Para los efectos de otorgar legitimidad a la sentencia, los jueces remarcaron la unanimidad de la decisión entre jurados populares y jueces técnicos:

Es decir que al dejar fijado el hecho, al abordar el aspecto subjetivo de la conducta atribuida al acusado, tanto los jueces técnicos como los legos optamos en forma unánime por descartar en (...) la intención de causar un sufrimiento a (...). (Cám. Crim. Río Tercero, Heredia, 2017). 


\section{Reflexiones finales}

En Córdoba, progresivamente se resuelven casos encuadrados en el marco de la figura de femicidio con jurados. Por una parte, los resultados cuantitativos muestran un creciente número de casos juzgados bajo la modalidad de juicio oral con jurados, sobredimensionados en hechos ocurridos entre personas donde existía una relación de un vínculo cercano sexo-afectivo (pareja, expareja, noviazgo, etc.). El mayor volumen de casos elevados a juicio con jurados indica una creciente persecución penal bajo este modo de juzgamiento. Por otra parte, el análisis cualitativo, elaborado sobre un corpus seleccionado a partir de la palabra femicidio, evidencia cómo la instalación de un discurso en torno a las conceptualizaciones de la violencia de género significó - y significa todavía - cuestionar estereotipos sociales patriarcales que justifican esa violencia. Esto implicó también redimensionar el alcance del contexto de la violencia de género privatizado en lo vincular para romper las fronteras del adentro/afuera como las de lo privado/ público.

Si bien el fallo del TSJ (S. 56, 2017) despega la violencia de género reducida al vínculo, es decir, del llamado femicidio íntimo, las sentencias recaen principalmente sobre este tipo de relaciones. Las decisiones se restringen al marco de lo privado, configurado en relaciones heterosexuales, donde víctima y victimario son definidos en términos de hombres y mujeres cisgénero. La reciente sentencia en la cual se juzgó como femicidio el homicidio de una mujer travesti y trabajadora sexual, y otras excepciones donde la violencia de género también es visibilizada en espacios públicos, complejizan la matriz de inteligibilidad. Por una parte, se cuestionan las categorías de interpretación que restringen derechos (muchas veces a instancias de movilizaciones sociales que acompañan a representantes de las víctimas), sin embargo, cada caso exige una mirada constante que complejice y evidencie las interpretaciones discriminatorias que se reproducen al operar el derecho como tecnología de género.

La participación de los jurados lleva a reflexionar sobre la necesidad de contar con una integración diversa en perspectivas de jurados del tribunal para abordar esta problemática constitutiva de las relaciones sociales. El rol fundamental lo tienen los operadores jurídicos - jueces/zas, fiscales, abogados/as_, ya que son ellos quienes van a 
plantear los términos del caso y disputarán el sentido de la violencia de género. En esta cuestión, resulta de importancia la implementación y puesta en funcionamiento de la Ley Micaela (Ley $N^{o} 27499$ ), dictada a finales de 2018, a la que la provincia de Córdoba se adhirió (Ley $N^{o}$ 10628) y que establece la capacitación obligatoria en género para todas las personas que integran los tres poderes del Estado.

Las sentencias hacen referencia a cuestiones estructurales que cimentan las relaciones de género: el patriarcado como sistema social y el machismo anclado en relaciones socio-culturales. En este sentido, frente a las interpretaciones judiciales pasionales centradas en aspectos individuales, donde la locura incluso justificaba la impunidad de la agresión (Sánchez et al., 2010), en el discurso jurídico actual emerge la dimensión estructural -la variable social de opresión y disciplinamiento patriarcal - en el fundamento de la punición. Por otra parte, la culpabilización de las mujeres como generadoras de la violencia es un discurso que pierde terreno en lo jurídico. Sin embargo, en las prácticas jurídicas de este análisis, los casos se inscriben en significaciones de extremos (pasivo/activo) y se reducen a relaciones vinculares cercanas (por ejemplo: matrimonio, noviazgo, etc.), lo que incide tanto en la reproducción de estereotipos de género binarios como en la aplicación restrictiva de la figura.

Desde el orden externo a los tribunales, los feminismos populares "hicieron estallar la diferenciación entre buenas y malas víctimas y, al mismo tiempo, pusieron en discusión la propia categoría de víctima" (López, 2019, p. 38); sostienen, a su vez, la necesidad de tramitar el miedo de una forma que no sea securitista ni punitivista (López, 2019). Como indica Arnés (2017), es innegable la necesidad de un sistema penal que garantice justicia, pero tampoco "los femicidios y las violaciones se acaban con la acción disciplinadora de la cárcel” (p. 1). Las críticas hacia el punitivismo penal conviven con la necesidad de justicia frente a casos que requieren de la perspectiva de género y sobre los cuales la "impunidad selectiva" (Arduino, 2018, p. 54) resulta relevante. Si bien los datos presentados permiten mostrar que esta impunidad resulta horadada, en orden de procurar sentencias más justas - y contribuir en el acceso a la justicia-, en contraparte, la punición se extiende. En este sentido, como sostiene Cano (2016) "si el prisma a través del cual inteligimos la violencia cis-hetero-patriarcal no se amplía y com- 
plejiza, en especial por fuera del marco del derecho, corremos el riesgo de invisibilizar aquello mismo que queremos iluminar" (p. 8).

\section{Referencias}

Arduino, I. (2018). Entre la victimización opresiva y la justicia emancipadora: Articulaciones entre feminismo y justicia penal. En M. Nijensohn (Ed.), Los feminismos ante el neoliberalismo. (pp. 51-62). Buenos Aires: La Cebra.

Arnés, L. A. (27 de abril de 2017). "Si tocan a una nos tocan a todas": Sobre feminismos, violencia machista y punitivismo". [Nota de opinión en Filo Debate]. (pp. 1-3). Recuperado de http:// investigacion.filo.uba.ar/sites/investigacion.filo.uba.ar/files/u6/Filo\%20Debate_Arnes.pdf

Bergoglio, M. I. (2017). The Dissemination of Jury Trials: A Reading from Argentina. Law \& Society Review, (51)3, 510-516. https://doi. org/10.1111/lasr.12282

Bergoglio, M. I. (2019). Introducción. En M.I. Bergoglio, M. E. Gastiazoro \& S. Viqueira, (Eds). En El estrado: La consolidación de las estrategias participativas en la justicia penal. (pp. 2-25). Córdoba: Advocatus.

Bourdieu, P. (2000). Poder, derecho y clases sociales. Bilbao: Descleé de Brouwer.

Cano, V. (abril, 2016). Crítica de la razón femicida: Sexualidad, amor y poder. Conferencia, III Jornadas Sexualidades Doctas. Facultad de Filosofía y Humanidades, UNC. Córdoba, Argentina.

Cano, V. \& Fernández Cordero, L. (2019).Vidas en lucha. Conversaciones. Buenos Aires: Katz.

de Lauretis, T. (1996). La tecnología del género. Mora. Revista del Área Interdisciplinaria de Estudios de la Mujer.(2), 6-34.

Equipo Latinoamericano de Justicia y Género. (28 de octubre de 2015). La interpretación del femicidio frente al ideal de buena víctima. Recuperado de http://www.ela.org.ar/a2/index.cfm?m uestra\&codcontenido $=2290 \&$ plcontampl $=12 \&$ aplicacion $=\mathrm{a}$ pp $187 \& \mathrm{cnl}=4 \& \mathrm{opc}=50$

Garita Vílchez, A. I. (2012). La regulación del delito de femicidio/feminicidio en América Latina y el Caribe. Ciudad de Panamá: Secretariado de la Campaña del Secretario General de las Naciones Unidas. Recuperado de https://assets-compromissoeatitude- 
ipg.sfo2.digitaloceanspaces.com/2013/09/UN2013_regulacionfeminicidio_AnaIsabelGaritaVilchez.pdf

Gastiazoro, M. E. (2018). Des-privatizar el sentido común sobre la violencia de género. Análisis de casos de femicidio en Córdoba, Argentina. RevIISE- Revista De Ciencias Sociales y Humanas, 11(11), 241-252. Recuperado de http://www.ojs.unsj. edu.ar/index.php/reviise/article/view/228

Jelin, E. (2010). Pan y afectos: La transformación de las familias. Buenos Aires: Fondo de Cultura Económica.

Kohen, B. (2000). El feminismo jurídico en los países anglosajones: El debate actual. En H. Birgin (Ed.), El derecho en el género y el género en el derecho. (pp. 73-106). Buenos Aires: Biblós.

Ley No 26150. Programa Nacional de Educación Sexual Integral. Boletín Oficial de la República Argentina, Buenos Aires, Argentina, 24 de octubre de 2006.

Ley No 26485. Ley de Protección Integral a las Mujeres. Boletín Oficial de la República Argentina, Buenos Aires, Argentina, 14 de abril de 2009.

Ley No 26618. Matrimonio Civil. Boletín Oficial de la República Argentina, Buenos Aires, Argentina, 22 de julio de 2010.

Ley No 26743. Identidad de Género. Boletín Oficial de la República Argentina, Buenos Aires, Argentina, 23 de mayo de 2012.

Ley No 26791. Código Penal, modificaciones. Boletín Oficial de la República Argentina, Buenos Aires, Argentina, 11 de diciembre de 2012.

Ley No 27499. Ley Micaela de Capacitación Obligatoria en Género para personas que integran los tres poderes del Estado. Boletín Oficial de la República Argentina, Buenos Aires, Argentina, 10 de enero de 2019.

Ley No 9182. Boletín Oficial de la Provincia de Córdoba, Córdoba, Argentina, 9 de noviembre de 2004.

Ley No 10628. Boletín Oficial de la Provincia de Córdoba, Córdoba, Argentina, 14 de junio de 2019.

Lizarralde, G. M. (9 de marzo de 2017). Recurso de Casación. Tribunal Superior de Justicia de la Provincia de Córdoba, Sala Penal, S. 56.

López, M. P. (2019). Apuntes para las militancias. Feminismos: Promesas y combates. La Plata: Estructura Mental a las Estrellas. 
Martínez, N. (julio, 2017). ¿Pueblo feminista? Notas sobre un feminismo popular. Ponencia, 9o Congreso Latinoamericano de Ciencia Política, Asociación Latinoamericana de Ciencia Política. Montevideo, Uruguay.

Oficina Regional para América Central del Alto Comisionado de las Naciones Unidas para los Derechos Humanos \& Oficina Regional para las Américas y el Caribe de la Entidad de las Naciones Unidas para la Igualdad de Género y el Empoderamiento de las Mujeres. (2014). Modelo de protocolo latinoamericano de investigación de las muertes violentas de mujeres por razones de género (femicidio/feminicidio). Panamá: Jeicos. Recuperado de http://www.ohchr.org/Documents/ Issues/Women/WRGS/ProtocoloLatinoamericanoDeInvestigacion.pdf

Resolución 1/2019. Protocolo para la atención integral de las personas con derecho a la interrupción legal del embarazo, actualización 2019. Ministerio de Salud Argentina. Boletín Oficial de la República Argentina, Buenos Aires, Argentina, 13 de diciembre de 2019.

Rodríguez, M. \& Chejter, S. (2014). Homicidios conyugales y de otras parejas. La decisión judicial y el sexismo. Buenos Aires: Editores del Puerto.

Sánchez, M., Gastiazoro, M. E., Rojo, V. \& Gilli, M. (octubre, 2010). Las representaciones de género en juicios por jurados. Ponencia, XI Congreso Nacional y I Congreso Latinoamericano de Sociología Jurídica y Coloquio Internacional, Facultad de Derecho Universidad de Buenos Aires y Sociedad Argentina de Sociología Jurídica, Buenos Aires, Argentina.

Segato, R. L. (2017). La guerra contra las mujeres. Buenos Aires: Traficantes de Sueños, Tinta Limón.

Smart, C. (2000). La teoría feminista y el discurso jurídico. En H. Birgin (Ed.), El derecho en el género y el género en el derecho. (pp. 31-71). Buenos Aires: Biblós.

Trebisacce, C. (2016). Una historia crítica del concepto de experiencia de la epistemología feminista. Cinta de Moebio, (57), 285-295. Recuperado de http://dx.doi.org/10.4067/S0717554X2016000300004

Turvey, B. E. (1999). Criminal profiling. An introduction to behavioral evidence analysis. Nueva York: AcademicPress. 
Unidad Fiscal Especializada en Violencia contra las Mujeres de la Nación (2017). Análisis de las primeras 50 sentencias por femicidio del país. Artículo 80 inciso 11 del Código Penal. A 5 años de la Ley 26.791. Recuperado de https://www.mpf.gob.ar/ ufem/files/2017/11/UFEM-Analisis_50_primeras_sentencias_femicidio.pdf 


\section{Anexo}

Tabla 1

Corpus de casos seleccionados - homicidios calificados o tentativa, en los cuales se nombra la palabra femicidio-febrero 2011-junio 2018, en la Provincia de Córdoba, Argentina

\begin{tabular}{|c|c|c|c|}
\hline Año & Imputado & Tribunal & $\begin{array}{l}\text { Fecha } \\
\text { sentencia }\end{array}$ \\
\hline 2011 & Ortega, N. D. & Cámara Octava en lo Criminal & $29 / 12 / 2011$ \\
\hline \multirow[t]{8}{*}{2015} & Ortega, D. T. & $\begin{array}{l}\text { Cámara Segunda de Río Cuarto } \\
\text { en lo Criminal }\end{array}$ & $12 / 03 / 2015$ \\
\hline & Tinari, D. M. & Cámara Primera en lo Criminal & $08 / 05 / 2015$ \\
\hline & Frías, H. R. & Cámara Séptima en lo Criminal & $10 / 06 / 2015$ \\
\hline & Rodríguez, A. A. & Cámara Séptima en lo Criminal & $12 / 06 / 2015$ \\
\hline & Carnero, N. O. & Cámara Séptima en lo Criminal & $22 / 09 / 2015$ \\
\hline & Medina, N. E. & Villa María en lo Criminal & $08 / 10 / 2015$ \\
\hline & Lizarralde, G. M. & Cámara Undécima en lo Criminal & $22 / 10 / 2015$ \\
\hline & Díaz, L. E. & Cámara Cuarta en lo Criminal & $13 / 11 / 2015$ \\
\hline \multirow[t]{12}{*}{2016} & Martínez, H. I. & Cámara Segunda en lo Criminal & $25 / 02 / 2016$ \\
\hline & Aragallo, W. O. & $\begin{array}{l}\text { Cámara Segunda de Río Cuarto } \\
\text { en lo Criminal }\end{array}$ & $09 / 03 / 2016$ \\
\hline & $\begin{array}{l}\text { González Brítez, } \\
\text { M. A. }\end{array}$ & $\begin{array}{l}\text { Cámara de Río Cuarto en lo } \\
\text { Criminal }\end{array}$ & $07 / 04 / 2016$ \\
\hline & Orellano, C. E. & Cámara Séptima en lo Criminal & $02 / 06 / 2016$ \\
\hline & Farías, J. H. & Cámara Tercera en lo Criminal & 08/08/2016 \\
\hline & Ferreyra, O. A. & Cámara Quinta en lo Criminal & $\begin{array}{l}22 / 08 / \\
2016\end{array}$ \\
\hline & $\begin{array}{l}\text { Bongiovanni, } \\
\text { M. D. }\end{array}$ & $\begin{array}{l}\text { Cámara de San Francisco en lo } \\
\text { Criminal }\end{array}$ & 08/09/2016 \\
\hline & López, R. J. & Cámara Undécima en lo Criminal & $16 / 09 / 2016$ \\
\hline & Consol, R. G. & $\begin{array}{l}\text { Cámara de Bell Ville en lo } \\
\text { Criminal }\end{array}$ & $13 / 10 / 2016$ \\
\hline & Herrera, J. G. & $\begin{array}{l}\text { Cámara Segunda de Río Cuarto } \\
\text { en lo Criminal }\end{array}$ & $07 / 11 / 2016$ \\
\hline & Achával, A. & Cámara Novena en lo Criminal & $20 / 12 / 2016$ \\
\hline & Oroná, A. F. & Cámara Séptima en lo Criminal & $29 / 12 / 2016$ \\
\hline
\end{tabular}




\begin{tabular}{|c|c|c|c|}
\hline \multirow[t]{6}{*}{2017} & Rivero, L. F. & $\begin{array}{l}\text { Cámara Río Tercero en lo } \\
\text { Criminal }\end{array}$ & $02 / 05 / 2017$ \\
\hline & Bernabé, M. C. & Cámara Tercera en lo Criminal & $24 / 07 / 2017$ \\
\hline & Busto, G. R. & Cámara Quinta en lo Criminal & $12 / 09 / 2017$ \\
\hline & Baldini, N. C. & Cámara Octava en lo Criminal & $27 / 10 / 2017$ \\
\hline & Heredia, G. A. & $\begin{array}{l}\text { Cámara Río Tercero en lo } \\
\text { Criminal }\end{array}$ & $08 / 11 / 2017$ \\
\hline & Aguilera, J. L. & $\begin{array}{l}\text { Cámara Segunda de Río Cuarto } \\
\text { en lo Criminal }\end{array}$ & $24 / 11 / 2017$ \\
\hline \multirow[t]{6}{*}{2018} & $\begin{array}{l}\text { Di Giovanni, } \\
\text { L. A. }\end{array}$ & $\begin{array}{l}\text { Cámara de Cruz del Eje en lo } \\
\text { Criminal }\end{array}$ & $22 / 03 / 2018$ \\
\hline & Lesta, E. I. & Cámara Séptima en lo Criminal & $14 / 05 / 18$ \\
\hline & Caruso, J. E. & $\begin{array}{l}\text { Cámara de Villa María en lo } \\
\text { Criminal }\end{array}$ & $15 / 05 / 18$ \\
\hline & Retamar, E. H. & $\begin{array}{l}\text { Cámara de Villa María en lo } \\
\text { Criminal }\end{array}$ & $20 / 07 / 2018$ \\
\hline & Salguero, J. C. & $\begin{array}{l}\text { Cámara Segunda de Río Cuarto } \\
\text { en lo Criminal }\end{array}$ & $23 / 07 / 2018$ \\
\hline & Cahuana, E. A. & $\begin{array}{l}\text { Cámara Primera de Río Cuarto en } \\
\text { lo Criminal }\end{array}$ & $24 / 07 / 2018$ \\
\hline Total & 33 & & \\
\hline
\end{tabular}

